\title{
4.3 Modern higher musicological education (PhD) in Ukraine: traditions and innovations
}

Music education and music pedagogy are integral components of music art as a complex system. It is at the level of these important areas is the process of comprehensive professional training of future musicians, associated with the translation and acquisition of professional knowledge, skills and abilities in all areas of music performance practice and music science.

The modern methodology of teaching a set of music-historical, music-theoretical and music-performing disciplines, which are basic for the formation of professional competencies at the third (educational-scientific) level of higher music education $(\mathrm{PhD})$, is based on close interaction of modern music-pedagogical science with the latest achievements in art history and humanities.

Today in this area there is a significant semantic renewal, generated by the requirements of modern art life and the huge expansion of the problem field of modern musicology and the growth of its scientific areas and new branches.

Music-pedagogical science as one of the fundamental branches of musicology and as a research area functions and develops in a wide cultural space of general humanities in constant integrative relations with socio-culturological (culturology, philosophy, aesthetics, history of culture, general history, pedagogy, psychology, etc.) and art (literary studies, theater studies, choreology) sciences.

At the beginning of the XXI century, an integral part of modern strategies for the development of theory and practice of music art is the widespread introduction of scientific achievements of musicology in the pedagogy of higher music education.

The philosophical and cultural component plays an extremely important role in music science and practice in recent decades. Modern musicology is increasingly saturated with culturological semantics, philosophical and aesthetic issues and methodology and is largely becoming a kind of philosophy of music or musical culturology. 
There are many reasons for such a sharp increase in the share of philosophicalaesthetic and musical-culturalogical thought in the field of musicology. On the one hand, "in modern musicology there is a clear tendency to self-knowledge as a specific worldview system, associated with the current total socio-cultural crisis of traditional humanistic (and primarily humanitarian) spiritual values and rethinking music science and music art of its place in a changing world and of its cultural functions" [268, p. 177]. On the other hand, the very range of branches of music science is expanding. Along with its fundamental components, relatively powerful new directions are actively and fruitfully developing, which have been formed both within the system of musicology itself and at the "junction" of musicology and related branches of science.

These substantive and structural transformations of music science have recently been increasingly reflected in music practice, including in the field of higher music education. An example of the above processes of structural-semantic and methodological self-renewal of music science of our time and their practical implementation at the level of training young scientists is the educational-scientific program "Musical Art" for the preparation of graduate students $(\mathrm{PhD})$ in this specialty [269]. This program is created by a team of scientists-musicologists, professors and lectures of the Department of Theory and History of Music of Kharkiv State Academy of Culture (among them - both authors of these article).

Describing the quality of this program, Doctor of Art Criticism, Professor, Head of the Department of Musical Medieval Studies and Ukrainian Studies of the Lysenko Lviv National Academy of Music Natalia Syrotynska notes: «The peer-reviewed educational and scientific program in the specialty 025 "Musical Art" was developed by $\langle\ldots\rangle$ leading Ukrainian scientists and teachers of music-theoretical, musichistorical and music-performing disciplines» [270, p. 1].

Emphasizing that «the priority of education quality as the core of modern educational policy, a determining factor in improving the efficiency of educational institutions and the development of their creative potential actualizes and intensifies the search for effective approaches to training future scientists and forms of its implementation» [271, p. 1], Doctor of Art Criticism, Head of the Department of 
Screen and Performing Arts and Cultural Studies of the Institute of Art History, Folklore and Ethnology after M. T. Rylsky of NAS of Ukraine O. Nemkovych accentuates that «exactly these priorities are inherent in the peer-reviewed educational and scientific program "Musical Art"》 [271, p. 1]. According to the scientist, "meaningful strategies of the program provide a combination of scientific and practiceoriented discourses of teaching future doctors of philosophy" [271, p. 1].

The purpose of this program, as noted by its authors, is primarily "training of highly qualified and competitive scientific and pedagogical staff and scientists of the new generation, capable of self-improvement and solving complex problems in research and innovation, scientific and creative, scientific and pedagogical, expert, informationalcommunicative, organizational and methodological activities in the field of music" [269, p. 6]. Meaningful strategies of the educational-scientific program envisage: 1) «combination of research-innovative and scientific-pedagogical components in the preparation of future doctors of philosophy; 2) interdisciplinary connections, synthesis of musical, philosophical and artistic-cultural discourses during research initiatives of graduate students; 3) realization of tasks of integrated musicology, which actualizes a new paradigm of scientific, in particular musicological thinking and provides unity of knowledge on history, theory and performing practice of musical art; 4) focus on the integration of domestic musicology in the world educational and scientific space in the context of cultural dialogue "East-West"» [269, p. 7].

Basic musicology disciplines are represented in the program at the level of both compulsory and elective educational components. Among such fundamental disciplines are the courses "Problems of modern musicology", "Methodology of theoretical musicology", "Methodology of historical musicology", "Organization and methods of musicological research", "Problems of performing musicology", "History and theory of musical performance", "Philosophy of music", "Musical aesthetics", "Ethnomusicology", "Ukrainian musical culture", "Innovative methods of teaching in higher educational institutions", etc. For example, in the curriculum of the discipline «Innovative teaching methods in higher education» the leading role belongs to the disclosure of the innovative nature of music pedagogy XX - early XXI century, 
highlighting the evolutionary transformations of higher music education XX - early XXI century in the context of changing artistic and pedagogical paradigms. Among the main content areas of the course - identifying innovative trends in professional music pedagogy and higher music education in the twentieth - early XXI century, identification of conceptual differences between modern and past music pedagogy, coverage of methodological principles and innovations in the system of music education in Ukraine, study of innovative methods of outstanding national musicianspractitioners, analysis of modern problems of distance learning in higher music education and prospects for its further development, as well as determining the characteristics of the leading author's innovative musical and pedagogical methods, systems and concepts of the XX - early XXI centuries [272].

In the context of actualization of research activities in the field of music art and professional development of scientific and pedagogical staff, the importance of mastering special methodological tools of musicology, an important component of which is theoretical musicology, is especially important.

The discipline «Methodology of Theoretical Musicology» is aimed at mastering the theoretical methods of studying musical phenomena and processes of development of musical art. A significant role in the course program belongs to the coverage of fundamental musicological categories and current issues of music in theoretical coverage, as well as the disclosure of features of music-theoretical concepts and the development of musicological thought of the past and present.

The concept of the course is aimed at forming a scientific and theoretical basis and enriching the experience of research musicology and professional competencies of graduate students, the ability to apply the acquired knowledge in the process of working on a dissertation in the field of music [273].

The course «Methodology of Theoretical Musicology» is designed to promote the expansion of professional thesaurus, the development of the intellectual level of graduate students, their research thinking, the pursuit of professional self-realization.

The main tasks of studying the discipline are: 1) awareness of the essence and specifics of theoretical musicology as a cognitive field; 2) formation of a holistic view 
of the content and structure of theoretical musicology and its role in the system of music sciences; 3) coverage of theoretical and methodological foundations of research activities in the field of musicology; 4) mastering the fundamental categories of theoretical musicology; 5) mastering the scientific-analytical and conceptual apparatus and methodology of theoretical musicology; 6) improvement and deepening of acquired and acquisition of new music-theoretical knowledge, skills, abilities and other competencies necessary for solving complex problems, implementation of independent scientific research and production of own ideas in the field of music art; 7) coverage of methodological approaches to the study of the phenomena of musical art and mastering the principles of using the methods of theoretical musicology in research activities; 8) determining the specifics of the historical development of theoretical musicology; 9) comprehension of the essence of leading music-theoretical concepts and application of their provisions in scientific-creative and practical activity; 10) creation of a theoretical basis for understanding the methodological foundations of the development of modern musicological knowledge; 11) mastering the technology of scientific and analytical generalization of the phenomena of musical art; 12) theoretical coverage of innovative musical-linguistic, stylistic and compositional technological processes in the practice of modern times; 13) revealing the artistic meaning and specifics of the phenomena of musical culture and art in theoretical discourse; 14) defining the essence of the leading music-theoretical concepts of the past and present; 15) determination of current issues and directions of research of modern domestic and foreign scientists in the field of theoretical musicology [273].

In the above-mentioned educational and scientific program of training doctors of philosophy in music in the graduate school of the Kharkiv State Academy of Culture a significant place is occupied by the study of the specifics and problem field of the performing musicology, presented at this level by the disciplines «Problems of Performing Musicology» and «History and Theory of Musical Performing». The leading role in the program of the course «Problems of Performing Musicology» is to reveal the specifics of performing musicology, highlighting its main problem areas, determining the place and role of performing musicology in modern musicology, as 
well as research phenomenology, theory and history of musical performance, modern methods of its study (first of all - problems of the performance-style analysis, determination of methodological features of performance comprehension of music of different epochs and styles, music-performance interpretation, communicativepsychological specifics of music-performance activity, etc.) [274].

The main theoretical and practical objectives of this course are 1) the formation of a holistic system of knowledge of performing musicology as a scientific field related to its formation and development, theoretical and methodological principles, structure, functions, major problem areas and leading current trends; 2) coverage of the history, theory and practice of musical performance, its phenomenological specifics, nature and role in the system of musical art; 3) identification of the fundamental role and specifics of the application of historical-stylistic, textological, genre and interpretive methods in modern theory and practice of performing musicology; 4) practical mastering of knowledge about historically determined performance-style and textual features of musical works of different epochs and about the corresponding methodological principles of their modern performance reproduction; 5) determination of historical and phenomenological specifics of performing styles, performing genres, performing interpretation, etc. [274].

The course «Contemporary Performing Arts in the Context of Intercultural Dialogue» is also aimed at providing graduate students with in-depth knowledge of the current state, general and specific patterns of contemporary performing arts in the context of intercultural dialogue. This course contains leading philosophical and musicological approaches to the study of contemporary performing arts, including the characteristics of world music performing schools and national artistic traditions.

In addition, the program contains a large number of the latest author's training courses (primarily at the level of elective educational components), which significantly expand the scientific horizons of graduate students and deepen their knowledge in various fields and problem areas of modern musicology.

A separate block of disciplines is related to the coverage of the specifics of nonEuropean musical cultures and the peculiarities of their interaction with the musical 
culture of Europe. Studying the courses «Musical Orientalistics», «History of Chinese Musical Art», «Traditional Musical Culture of the Asian Region» allows to significantly deepen the scientific ideas of graduate students about the musical art of non-European civilizations in the context of cross-cultural dialogue «East - West».

The course «Musical Orientalistics» aims to understand the nature of European musical orientalism in general and the musical images of the East as exotic objects of art. The concept of the course «Traditional musical culture of the Asian region countries» is aimed at expanding the professional thesaurus, the development of intellectual level and research thinking of graduate students, the pursuit of professional self-realization. The course aims to help enrich graduate students with new knowledge and creative experience in understanding the determinants and specifics of the development of musical art of non-European cultural tradition and the nature of modern attitude to it. The discipline is aimed at forming a theoretical basis for research musicological activities and professional competencies of graduate students, the ability to apply the acquired knowledge in the process of working on a dissertation in the field of music. The main emphasis in the study of the discipline is on the cultural problems of the history of musical art in Asian region on the original artistic material of its national music. Disclosure of the general picture of Asian musical cultures and highlighting the consistent evolution of national styles and genres is carried out in the dialectic of tradition and innovation and chronologically covers the range from the model of musical thinking of the ancient world to contemporary music [275].

The course «History of Chinese Musical Art» should help graduate students to get an idea of musical sinology as a field of musicology, learn the basic features of the formation and development of Chinese musical art as a cultural phenomenon, identify its cultural-historical, philosophical, ethical and literary-poetic principles, to reveal the specificity of genre-stylistic evolution of China music, to highlight the creative activities of prominent Chinese musicians of the XX - early XX centuries. XXI century, as well as to characterize contemporary Chinese musical art and determine its role in the world culture of the late XX - early XXI centuries [276]. 
In turn, the courses «Sociology of Music», «Phenomenology of Music», "Philosophy of Music", «Psychology of Musical Art», «Evolution of Musical Styles and Directions» represent, first of all, thorough directions of modern music science and practice. The course "Philosophy of Music" studies the specifics of musical life, ontological principles and phenomenology of musical creativity, reveals the essence of musical and aesthetic ideas and views on music as a sound model of the universe and an analogue of personality [277]. Problems of musical creativity are considered in philosophical, aesthetic and artistic discourses, using knowledge of the history of musical culture, the specifics of genre and style development of music, as well as modern transformational processes in art and information space and the latest laws of artistic communication. This determines the close ties of the course with the humanities and professionally-oriented professional musicological disciplines, which by their generalizations enrich of the idea of music as an art and expand the analytical tools of musicology [277]. The course «Musical Sociology» forms graduate students' knowledge of the specifics, methodology and problem field of musical sociology as an important branch of modern musicology, highlights the historical development of musical and sociological thought in European culture, reveals leading musical and sociological ideas and concepts of prominent musicologists XX - XX centuries [278]. The course is aimed at providing graduate students with a modern theoretical and methodological basis for qualified research work in the field of sociology of music.

Courses «Modern Composer Technologies», «Music Journalism», «Types of Music Communication», «Jazzology», «Management of Art Research Projects» contribute to the deepening of the professional and technological specifics of various areas of activity important for the functioning of modern music.

The course «Musical Culture of Slobozhanshchyna» deepens the knowledge of the past and present of the musical culture and art of the Kharkiv region.

Thus, modern Ukrainian musicological education at the level of postgraduate study organically combines basic music-theoretical and music-historical disciplines with a wide range of new author's courses, which significantly expand the worldview and professional horizons of future scientists $-\mathrm{PhD}$ in speciality Musical Art. 